\title{
Applications of Nano Technology in textile mills in Madurai, Coimbatore and Mumbai
}

\author{
S. Geethadevi \\ Dept. of EEE \\ Aurora Scientific and \\ Technological Institute \\ Uppal, Hyderabad, India
}

\author{
M. Rajkumar \\ Dept. of EEE \\ Dhanalakshmi Srinivasan \\ College of Engineering and \\ Technology \\ Mamallapuram \\ Chennai, India
}

\section{J.Ganesan}

Dept. of EEE

Sree Sowdambika College of

Engineering

Aruppukottai, India
D. Edison Selvaraj

M. Rajmal Joshi

Dept. of EEE

Panimalar Engineering College

Chennai, India

Division of High Voltage

Engineering, College of

Engineering, Guindy

Anna University, Chennai

India

\begin{abstract}
This paper deals with the applications of nano coated motors in Textile mills present in Indian Smart Cities such as Mumbai, Madurai and Coimbatore. Black soil is present mostly in these cities. They are suitable for the growth of cotton. So, many textile based industries are present in these cities. Many motor manufacturing companies are also present in these cities to design, model and create new innovative machines used for the textile industries. Some special machines are also used for the textile mills. One of the special machines is nano coated induction motor. These types of nano coated motors are called as special machines because they are having nano coated enamel on their windings. Their performance is very good when compared to that of the normal induction motor. The quality of the industries was improved by using the nano coated motors. This paper shows the literature about the applications of nano coated motors in Textile mills in Indian cities.
\end{abstract}

Keywords: Nano coated motors, Textile mills, Madurai, Coimbatore, and Mumbai

\section{INTRODUCTION}

The industrial applications of nano electrical drives are numerous. In India, textile mills are numerously present in Mumbai. Hence, Mumbai is also called as Manchester of India. Especially, in Tamil Nadu, textile mills are mostly located in Coimbatore, Erode, Tiruppur and Madurai. So, Coimbatore is called as Manchester of South India. Electrical motors are mostly used for Textile applications for various operations. Hence, motor manufacturing companies are present in Coimbatore. It is also one of the biggest cities in India. It is the third largest city in Tamil Nadu next to Madurai. Madurai, Coimbatore, Erode and Tiruppur cities are announced as Smart cities in India to improve the infrastructure and all the facilities in these cities [1]. To select a particular motor for a given application, knowledge of the following things is very much necessary.

1. The torque speed characteristics of the industrial load are important. This selects the type of motor used to drive the load.
2. The environmental conditions in the industry where the motor is used. This decides the ambient temperature at which the motor operates.

3. Duty cycle of the load and the frequency of starting and braking. The KW rating of the motor is decided by the load cycle. Very frequent starting and braking of the motor alters the $\mathrm{KW}$ rating of the motor.

4. Speed control decides the type of motor.

5. Nano Electric motors are employed as drive motors in many applications such as

- Textile mils

- Cranes and hoists

- Steel rolling mills

- Paper mills

- Cement mills

- Machine tool applications

- Sugar mills

- Turbo compressors 
- Coal mining

- Centrifugal pumps

- Ball mills

\section{PROCESS INVOLVED IN TEXTILE MILLS}

The The several process involved in textile mills by the time the finished cloth comes out of a mill from its basic raw material, cotton picked up from the fields are

1. Ginning

2. Blowing

3. Cording

4. Drawing

5. Combing

6. Spinning

7. Looming

The requirements of the motors are different for different process. Drive consideration for textile mills

\subsection{Ginning}

The process of separating seeds from the picked raw cotton obtained from the field is called as ginning. This might be done in the mills located near the fields or in the industrial location itself [2]. The ginned cotton is transported to the industrial area in the form of bales. Speed range of ginning motors is 250 to $1450 \mathrm{rpm}$. The load speeds are nearly constant. No speed control is needed. Squirrel cage induction motors are used for this purpose [3]. High efficiency squirrel cage induction motor or nano coated cage motors may be used to improve the quality of ginning.

\subsection{Blowing}

The ginned cotton in the form of bales is opened up and is cleaned up in a blowing room. Three phase induction motors are used for this purpose. Speed control is not required. Synchronous speed of the motor is 1000 or $1500 \mathrm{rpm}$. Energy efficient nano coated motors can also be used for this purpose to improve the time of motors used in textile mill.

\subsection{Cording}

Cleaned cotton is converted into laps by the means of lap machines. 3 phase squirrel cage induction motors are used as lap machines. Cording is the process of converting laps in to slivers.

Requirements of the cording motors

1. The motor used for cording should have a large moment of inertia to accelerate the drum.

2. The motor has to withstand prolonged accelerating periods.

3. The motor should have high starting torque.

4. It should also have low starting current so that the starting losses should be Minimum.

5. The motor must have sufficient thermal capacity to with stand the heat produced by the losses which are occurring under the prolonged acceleration period.

The specifications for cord motors are given in standard IS: 2972, 1964. 3phase totally enclosed far cooled squirrel cage Induction motors with high starting torque are used. The rating of the motor depends upon the type of fabric. For light fabric, 1.1 to $1.5 \mathrm{KW}$ motors are used whereas for heavy fabric, motors with rating of 2.2 to $5.5 \mathrm{KW}$ may be used. The operating speed of the motors is in the range of 750 to 1000 rpm. Normally squirrel cage motors having $8 / 6$ poles with the speed range of 750 to $1000 \mathrm{rpm}$ are used. Based on the literature survey carried on the applications of nano fillers used in the electrical motors, nano cage motors (or) nano filler mixed enamel coated 3 phase squirrel cage induction motors with the above mentioned speed range can also be used to improve the performance of the textile mills. Nano coated motors have the following advantage.
1. High efficiency
2. Lower harmonics
3. Higher thermal withstanding capacity
4. Improved power factor
5. Good speed regulation
6. Reduced EMI
7. Improved speed - torque characteristics

Slip ring Induction motors is used with rotor resistance starters to give high starting torque at low starting current. The operation is continuous uninterrupted.

\subsection{Drawing}

Drawing machines are used to convert the slivers into uniform straight fibre. The motor must be capable of stopping instantaneously, in case of sliver breaking. The drawing machines are self brake motors. The motor is also subjected to inching to place up the broken sliver again. The inching operations are 20 in amount. There is no necessity for a clutch when the brake forms an integral part of the motor. Hence the motor becomes compact.

\subsection{Combing}

Combing and lap operation take place after the drawing process. The combing process is used to upgrade the fibre. The slivers are converted into laps before combing. Normal squirrel cage motors are used for these operations. Spinning is the next process after combing and lap operations.

Requirements for spurring motors

1. Motor should have smooth acceleration to drive the speed frame.

2. The motor should be capable of working in high ambient temperatures.

3. The motor must be totally enclosed to prevent the cotton fluff getting deposited on the motor surface.

4. The motor must have slow, smooth and uniform acceleration having thermal reserve to avoid yarn breakage.

5. The spinning motor must be capable to do: Drawing, Twisting and Winding operations.

6 . Its starting torque must be $150-200 \%$ and the peak torque should be $200-250 \%$.

7. The motor must have an acceleration time of 5to10s.

8. The operating speed is 500rpm.

9. The KW rating of the motor is decided by

a. Ring frame

b. Number of spindles.

c. Ring diameter.

d. Spindle speed.

10. A normal motor is not suited for spinning operations. A two speed pole change motor may be used. These motors are bulky and costly. But, it has several advantages.

- It allows setting of any speed difference by adjusting the pulley diameters and speed ratios.

- The yarn tension can be adjusted independently.

- There is no interruption in production even when one motor fails. 
Before the thread is ready for spinning it is thinned down in two or three stages by processing it on a speed frame. The strengthened yarn is wound on bobbins.

For mule spinning a group drive may be employed. The motor should have high starting torque and operating slip. A slip ring motor with rotor resistance control or high torque cage motors may be used. Nano coated motors can also be used.

For operation like winding, warping and sizing, normal motors are used. Low speed motors are used. Reduction in speed using a gearing unit may be done. When the yarn is transferred from the Bobbin, a speed drop of nearly 100rpm is necessary. So, for these operations, high slip motors are used.

\subsection{Looming}

The weaving of yarn in to cloth is called as looming. It is done in looms. The drives may be either semi group drives or individual drives depending upon the quality of the required cloth. The speed required is 600 to $750 \mathrm{rpm}$.

Requirements of a loom motor

1. Starting torque must be high.

2. The duty cycle consist of frequent starting stopping. Clutch may be used to avoid frequent starting and stopping of the motor.

3. The operation requires a reciprocating mechanism. A flywheel is used for smoothing and to avoid current and tuque pulsations present during and conversion of rotary motion to linear reciprocating motion.

4. Totally enclosed should be used to avoid burring of the cotton fluff due to motor heating.

5. Loom motors must withstand the effects of humidity.

6. Speed of the motors is in the range of 100 to $750 \mathrm{rpm}$.

The loom motors are normally 3 phase Induction motors with high starting torque. These motors are totally enclosed and fan cooled. The fan cooling is used to avoid the collection of cotton fluff on the motor surface.

i. The motor deign depends upon the following parameters:

ii. Torque and current pulsations due to reciprocating motion frequent starting and stopping decided the KW rating of the motor.

iii. Fabric decides the size of the motor. For light fabric, motors of rating up to $1.5 \mathrm{KW}$ are used while motors of rating 2.2 to $3.7 \mathrm{KW}$ are employed for heavy fabric.

7. Brake motor is used to stop the motor in the cage of thread breaks. Special design of textile mill motors are required owing to the location of the motor, running condition and the torque requirements while staring. In textile mills, the motors are located in places where there is a lot of dust. The cotton fluff may be deposited on the motor causing the following on the effects

i. It affects natural cooling of the motor.

ii. It caused the temperature rise of the motor.

iii. It increases the electro static discharge and EMI. To prevent these effects, the following suggestions are made.

- Totally enclosed and fan cooled motors are used.
- Nano coated motors having lower temperature rise and reduced EMI shall be used. It can also improve the quality of the textiles and its performance. It has been proved from various experiments.

\section{ALGORITHM FOR THE DESIGN OF NANO MOTORS}

1. Manufacture the nano fillers by using ball mill method

2. Augment the particle size by using SEM analysis [4]

3. Mix the nano fillers and the enamel by ultrasonic vibrators

4. Coat and impregnate the windings of different types of motors with the various nano fillers

5. Test the different nano coated motors [5]

6. Compare the results

7. Justify the nano coated motor which is having the superior characteristics when compared to other motors.

\section{EXPERIMENTAL WORKS NEEDED FOR THE DESIGN OF NANO MOTORS}

1.Ball mill was used to manufacture the nano fillers used in nano coated motors used in Textile industries. $\mathrm{Al}_{2} \mathrm{O}_{3}, \mathrm{SiO}_{2}$, $\mathrm{TiO}_{2}, \mathrm{ZrO}_{2}, \mathrm{ZnO}, \mathrm{SiC}$ were used as nano fillers used in nano coated motors [6].

2. SEM was used to augment the particle size of fillers before and after Ball milling process.

3. Ultra sonic vibration process was used to mix the enamel and nano fillers [7]

4. Nano filler mixed enamel was used as the coating and impregnation for the windings of the motor [8].

5. Different types of testing were conducted to determine the performance of the nano coated motor. They were

a. Direct loading [9]

b. Temperature test

c. Harmonics Measurement

d. EMI Measurement [10]

6. The readings should be taken and compared between the different types of nano coated motors used in Textile mills.

\section{ADVANTAGES OF NANO COATED MOTORS}

The following are the advantages of nano coated motors:

1. Higher efficiency [11]

2. Wide operating temperature range

3. Reduced Harmonics

4. Reduced EMI

5. Increased life time

6. Reduced losses

7. Improved Cooling

8. Reduced noise

9. Lesser amount of powder to produce large output

10. The quality of the industries will be increased by these motors.

\section{LIMITATIONS OF NANO COATED MOTORS}

The most important drawbacks of nano coated motors are: 
1. Powder manufacturing is time consuming

2. Expensive equipments were employed for synthesis and characterization of nano fillers

\section{CONCLUSIONS}

In the upcoming future, the use of nano coated motor in textile mills can bring the following considerable changes when compared to the conventional motors used in textile mills.

1. Improvement of accuracy and quality of the output

2. Enhancement of the life time of the machines

3. Reduction of the maintenance cost

4. Improvement of thermal withstanding capacity

5. Improved slip, power factor, speed torque characteristics and efficiency. So nano coated motors can be used in the machine tools.

6. Reduction of vibrations and noise.

\section{ACKNOWLEDGEMENT}

We express our sincere thanks to the God, the Almighty, and Lord Jesus Christ. We express our gratitude towards our Tamil Scientist Dr. A.P.J. Abdul Kalam. We express our deep heart feelings towards His death.

\section{REFERENCES}

[1] Edison selvaraj. D, et.al Applications of Nano Technology in Pyro Industries located in Sivakasi, International Journal of Science and Engineering Applications Volume 4 Issue 4, 2015.

Edison Selvaraj. D, et.al "Estimation of Losses on $3 \Phi$ Nano Coated Induction Motor" Applied Mechanics and Materials Vol.666 (2014) pp. 213217 (2014) Trans Tech Publications, Switzerland.

[3] Edison Selvaraj. D, Pugazhendhi Sugumaran. C, Lieutenant Ganesan. J, Ramathilagam. J, “Analysis of Dielectric and Thermal Properties of Polyamide Enamel Filled with Carbon Nano tubes" International Journal of Nano science, Vol.12, Issue 3, June 2013.

[4] Edison Selvaraj, D., C. Pugazhendhi Sugumaran, and A. Sivaprakash "Characterization of Electrical and Thermal Properties of Enamel Filled with Carbon Nanotubes", Proceedings of the Third International Conference on Trends in Information, Telecommunication and Computing, Springer New York, 2013.

[5] Selvaraj, D. E., Priyan, S. S., Joshi, M. R., Sugumaran, C. P., Kannan, R., Raj, R. A., Kumar, B. M., Prakash, R., Ganesan, J., Krishnamoorthi, D., \& Kumar M. R, "A Review on The Nano Fillers Used for Electrical Apparatuses", Journal Club for Electrical Engineering (JCEE), Vol.1, Issue 1, pp 8 -17, Aug 2014.
Selvaraj, E. D., Priyan, S. S., Joshi, M. R., Sugumaran, C. P., Kumar, B. A., Kumar, M. A., Kumar, S. A., Khan, A. H., Kannan, R., Ganesan, J., Kumar, R., Kumar S. D, "A Review on theFabrication Methods Used in Nano Technology for The Fabrication of Nano Fillers Used in Electrical Apparatuses", Journal Club for Electrical Engineering (JCEE), Vol.1, Issue 1, pp , Aug 2014.

Joshi MR Selvaraj DE, Kumar GS, Mohan BR, Sugumaran CP, Kumar RM, Ganesan J, "A Lecture Notes for Understanding the Fundamentals of Fabrication of Nano Fillers", Journal Club for Electrical Engineering (JCEE), Vol.1, Issue 2, pp 1 -16, Oct 2014.

Edison Selvaraj. D, Ruban Karthik. C, Arun. R, Geethadevi. S and Ganesan. J, "Energy Efficient Three Phase Squirrel Cage Induction Motor Fed AC Drives" in International Journal of Science and Engineering Applications, Vol.3, Issue2, pp.18-21, 2014.

Edison Selvaraj. D, Pugazhendhi Sugumaran. C. Dr. , Shrikrishna V. Kulkarni, Sukumar Mishra, Ganesan. J, Raj Kumar.M, Geethadevi. S, "Energy efficient DC shunt motor fed drives" International Journal of Electrical and Electronic Science 2014; 1(1): 12-17.

Edison Selvaraj. D, Pugazhendhi Sugumaran. C, Ganesan. J, Rajkumar. M, "Nano Filler Mixed EnamelCoated Single Phase Capacitor Run Induction Motor" in Global Journal of Researches in Engineering, GJRE Volume $\quad 14$ Issue 6 Version 1.0, pp.1-8, August 2014.

Edison Selvaraj. D, Pugazhendhi Sugumaran. C, Krishnamoorthi. D, Raj Kumar. M, Ganesan. J, Geethadevi. S, Rajaram. K, Dinesh Kumar. S, "Improvement of Efficiency and Thermal Withstanding Capacity of Single Phase Induction Motor" in European Journal of Academic Essays 1(5): 10-15, 2014. 